\title{
Protocol Administratively Withdrawn
}

National Cancer Institute

\section{Source}

National Cancer Institute. Protocol Administratively Withdrawn. NCI Thesaurus. Code C70778.

A clinical study protocol status designating the protocol that has been withdrawn prior to the complete review. 